\title{
Políticas de Participação de Estudantes: Psicologia na Democratização da Escola
}

\author{
João Paulo Mendes Carvalho Jacqueline Meireles \\ Pontificia Universidade Católica de Campinas, SP, Brasil. $\quad$ Pontificia Universidade Católica de Campinas, SP, Brasil. \\ Raquel Souza Lobo Guzzo \\ Pontifícia Universidade Católica de Campinas, SP, Brasil.
}

\begin{abstract}
Resumo: Este trabalho objetiva realizar levantamento e descrição das políticas de participação de estudantes na escola, identificar os métodos propostos para a efetivação destas políticas e traçar reflexões sobre como a Psicologia Escolar pode contribuir no desenvolvimento destas propostas. Articula as contribuições da educação dialógica defendida por Paulo Freire e os pressupostos da Psicologia Crítica Alemã, a fim de construir um referencial para a atuação do psicólogo na escola com vistas ao fortalecimento e autonomia dos sujeitos. Trata-se de uma pesquisa de caráter documental que usou como fonte de dados, leis e planos de educação das esferas Federal, Estadual e Municipal e o regimento escolar da cidade de Campinas. Os resultados evidenciaram que, apesar da existência de leis específicas que assegurem a participação de estudantes como necessária para a gestão democrática, a efetivação destas práticas ainda precisa encontrar caminhos para se concretizar. A partir disso, refletiu-se sobre como as ações da Psicologia na escola têm potencialidades para favorecer o fortalecimento dos espaços participativos, visando o desenvolvimento das capacidades de diálogo, negociação e resolução não violenta dos problemas cotidianos.
\end{abstract}

Palavras-chave: Participação, Psicologia Escolar, Gestão Democrática.

\section{Students' Participation Policies: the Role of Psychology in the Democratization of the School}

\begin{abstract}
This work aims at carrying out a survey and description of students' participation policies in schools, in addition to identifying methods for the implementation of these policies and reflecting on how School Psychology can contribute to the development of these proposals. It articulates the contributions of the dialogical education defended by Paulo Freire and the assumptions of the German Critical Psychology in order to build a framework for psychologists in schools and thus help them strengthen and promote the autonomy of the subjects. The data sources for this documental study were the educational plans of the federal, state and municipal levels and the school charter of the city of Campinas, Brazil. The results showed that, despite the existence of specific laws that deem students' participation necessary for democratic management, the implementation of these practices still needs to find ways to come about. With that in mind, we reflected on how psychologists' actions in schools can strengthen participatory spaces and thus develop capabilities like dialogue, negotiation and non-violent resolution of daily problems.
\end{abstract}

Keywords: Participation, School Psychology, Democratic Management. 


\title{
Políticas de Participación de Estudiantes: Psicología en la Democratización de la Escuela
}

\begin{abstract}
Resumen: Este trabajo tiene como objetivo realizar el levantamiento y descripción de las políticas de participación de estudiantes en la escuela, identificar los métodos propuestos para la efectividad de estas políticas y trazar reflexiones sobre cómo la Psicología Escolar puede contribuir en el desarrollo de estas propuestas. Articula las contribuciones de la educación dialógica defendida por Paulo Freire y los presupuestos de la Psicología Crítica Alemana, a fin de construir un referencial para la actuación del psicólogo en la escuela con vistas al fortalecimiento y autonomía de los sujetos. Se trata de una investigación de carácter documental que usó como fuente de datos, leyes y planes de educación de las esferas Federal, Estadual y Municipal y el regimiento escolar de la ciudad de Campinas. Los resultados evidenciaron que, a pesar de la existencia de leyes específicas que aseguran la participación de estudiantes como necesaria para la gestión democrática, la efectividad de estas prácticas todavía necesita encontrar caminos para concretarse. A partir de eso, se reflexionó sobre cómo las acciones de la Psicología en la escuela tienen potencialidades para favorecer el fortalecimiento de los espacios participativos, visando el desarrollo de las capacidades de diálogo, negociación y resolución no violenta de los problemas cotidianos.
\end{abstract}

Palabras clave: Participación, Psicología Escolar, Gestión Democrática.

\section{Introdução}

O presente artigo parte de uma experiência de extensão que o Grupo de Pesquisa "Avaliação e Intervenção Psicossocial: Prevenção, Comunidade e Libertação" tem desenvolvido no âmbito das escolas públicas no município de Campinas-SP. Com início em 2014, o projeto denominado Ecoar (Espaço de Convivência, Ação e Reflexão) visa o enfrentamento da violência pela construção e fortalecimento de espaços de diálogo e participação. Os espaços participativos assegurados por legislações representam avanços no fortalecimento da Democracia, mas psicólogos da equipe têm observado que poucos são os atores escolares que os conhecem, o que pode contribuir para a reprodução da passividade e distância da vida política, que se produz fora da escola.

Apresentam-se, aqui, resultados de uma pesquisa realizada com objetivo de identificar quais são as propostas no âmbito Federal, do estado de São Paulo e do município de Campinas, que incentivam e/ou garantem a participação de estudantes na construção das escolas públicas e compreender como elas propõem esta participação. Para isso, buscou-se identificar e descrever em que momentos a participação de estudantes é mencionada nestas políticas; quais métodos são propostos para sua efetivação e, por fim, traçar reflexões sobre como a Psicologia pode contribuir no desenvolvimento destas propostas.

O texto é organizado por meio de três eixos de fundamentos teóricos: no primeiro, parte-se de uma análise sobre a subordinação da Democracia ao sistema Econômico, trazendo uma reflexão sobre o papel político da Psicologia; no segundo, a Psicologia Crítica Alemã é apresentada e articulada com as contribuições de Paulo Freire, a fim de tecer fundamentos para a atuação de uma Psicologia comprometida com o processo de democratização da sociedade, por meio de sua atuação no âmbito das escolas públicas. Por fim, discute-se a importância da gestão democrática das escolas e apresenta-se os espaços nos quais os estudantes têm direito à participação. Na seção Método é detalhada a realização de uma análise documental de Legislações e Planos de Educação, e os resultados apresentam-se conforme as esferas Federal, Estadual e Municipal, por meio de uma articulação com os referenciais teóricos. Essa pesquisa resultou na formulação de uma cartilha denominada "Participar da minha escola", que visa informar e mediar discussões com estudantes e educadores sobre os espaços de participação nas escolas. 


\section{Fundamentos teóricos}

\section{Democracia e Psicologia}

Discorrer sobre a Democracia não é discorrer sobre algo "consolidado", mas que está em um processo permanente e que sofre redefinições e transformações estruturais conforme o tempo e local (Dahl, 2012). Partimos do pressuposto de que não há como discutir o domínio Político sem compreender sua subordinação ao Econômico no âmbito do sistema capitalista, de forma que o processo histórico de transformações que levaram ao sistema político em que vivemos, foi orientado pela luta de classes, predominando os interesses do poder hegemônico (Boechat, 2017; Lombardi, \& Lima, 2017; Ponce, 2005; Wood, 2003). Martin-Baró (1990) reforçava a necessidade de adjetivação da Democracia, principalmente no contexto político latino-americano, em que a instauração de regimes democráticos formais mascara as formas de dominação tradicionais, com vistas a desarticular prática e teoricamente as lutas populares.

Conforme aponta Wood (2003), o sistema capitalista afirma a igualdade cívica de todas as pessoas, ao enquadrá-las como cidadãs, independentemente de sua posição socioeconômica. Porém, esta cidadania não terá qualquer poder de alcance sobre as estruturas que constroem as desigualdades de classe, tendo em vista as relações de produção capitalistas, que garantem o direito de apropriação do trabalho excedente ao proprietário, mesmo sem uma condição de privilégio jurídico ou civil (visto que todos são supostamente iguais). Sobre este processo, Saviani (2017) aponta que, ao dividir o Soberano (povo) em duas classes distintas (os detentores dos meios de produção, e os que sobrevivem de sua força de trabalho), a sociedade moderna dificulta a indicação de governantes que representem os interesses populares. Desta forma, resta a elas a escolha, dentre os candidatos indicados pelos grupos dominantes, da pessoa que seria "menos pior". Evidencia-se, assim, a tendência de distanciar o povo da real possibilidade de participar na construção política do país, deixando-o mais susceptível à exploração. Neste contexto, pode-se afirmar a formalidade do regime democrático que se instaurou no Brasil, como em diversos outros países submetidos à exploração pelo chamado primeiro mundo. Para Saviani (2017), esta formalidade é insuficiente, pois precisa avançar no sentido de uma demo- cracia real, mas é, ainda assim, necessária, ao garantir o mínimo de regras que devem ser respeitadas para a garantia de direitos dos cidadãos.

Em sua obra "Democracia, Agência e Estado", O’Donnell (2011) aponta que o regime democrático precisa ofertar um conjunto de leis e instrumentos que promulgam e protegem a potestas dos indivíduos, ou seja, sua capacidade de exercer a própria vontade nos âmbitos permitidos. Lombardi e Lima (2017) observam que na história brasileira, a ampliação destes instrumentos ou da participação popular efetiva por meio deles, sempre foi vista como uma ameaça aos interesses das elites. Apontam ainda, que em Estados frágeis, característicos da periferia capitalista, a forma de lidar com estas ameaças tem sido pela quebra do ordenamento jurídico, por meio de um Golpe de Estado. Assim, os autores apresentam um panorama dos Golpes de Estado que se realizaram pelos mais diversos atores e meios no Brasil, desde a Proclamação da República, sempre com vistas aos interesses dominantes.

Neste sentido, Lucena, Previtali e Lucena (2017) organizaram um livro composto por capítulos de diferentes autores que demonstram a quebra no ordenamento jurídico no processo de impedimento de Dilma Rousseff, em 2016. Estamos assim, vivenciando um novo golpe, cujas consequências já se apresentam como devastadoras aos grupos populares: as "Reformas de fachada", conforme expressa Villen (2017), como a Proposta de Emenda Constitucional - PEC $\mathrm{n}^{\circ} 55$ (2016), que congela os gastos do Estado pelo período de 20 anos, condenando os bens e serviços públicos ao sucateamento; a Reforma Trabalhista, que legitima a flexibilização dos direitos trabalhistas e atacam o direito à aposentadoria (Lei № 13.467, 2017); a Medida Provisória ${ }^{\circ} 746$ (2016), que foi aprovada sem consulta à sociedade; a Reformulação do Ensino Médio, que torna a formação ainda mais passiva e técnica voltada, apenas, aos interesses do mercado, dentre muitos outros exemplos que se poderia elencar.

Essas medidas antidemocráticas afetam, diretamente, as políticas públicas nas quais se insere a(o) profissional de Psicologia. Segundo Hur e Lacerda Junior. (2017), a partir da década de 1980, o Conselho Federal de Psicologia (CFP) passou a direcionar suas ações para questões sociais e políticas, tendo importante papel na redemocratização do país após os anos de Ditadura empresarial-militar. A categoria teve participação no movimento das Diretas Já e na formulação da Constituição cidadã, que deu origem 
a políticas como o Sistema Único de Saúde - SUS (em 1988) e o Sistema Único de Assistência Social - SUAS (em 1993). Os autores apontam, ainda, que a partir da década de 2000, a inserção de psicólogos nas políticas públicas passa a ser uma bandeira do CFP, e muitos profissionais passaram a atuar nestes campos (principalmente nas políticas sociais) com uma multiplicidade de posicionamentos e práticas.

Prado (2014) discute que, ainda que a entrada do psicólogo no campo das políticas tenha sido tardia, a relação da Psicologia com a Política tem uma história longa, pois ao final do século XIX os conhecimentos psicológicos já eram utilizados para explicar fenômenos políticos. Limitados por metodologias individualistas e descontextualizadas do cotidiano de vida da população, muitos destes conhecimentos eram psicologizantes, no sentido de buscar explicações individuais para fenômenos sociais, e atribuir patologias aos desajustados da sociedade. Ainda que profissionais de Psicologia não o reconheçam, seus posicionamentos serão, necessariamente, políticos: "Podem estar implicadas com a emancipação e transformação, mas também com o seu reverso, seja a captura pelas estigmatizações e disciplinarizações, a opressão da violência de Estado, a exclusão promovida pelo neoliberalismo etc." (Hur, \& Lacerda Junior, 2017, p. 4).

Para Boechat (2017), parte da Psicologia, que atuou nas lutas populares trazendo importantes contribuições para a redemocratização da sociedade, acabou por limitar suas ações ao campo da emancipação política, deixando de discutir estratégias que a superem no sentido de uma emancipação humana ${ }^{1}$. Isso porque seu compromisso social está voltado, unicamente, para o desenvolvimento da democracia participativa e da cidadania, contribuindo para a manutenção das ilusões de que é possível a emancipação em uma sociedade que se estrutura na desigualdade. Desta forma, a Psicologia deve contribuir de forma tática para o fortalecimento das relações democráticas, diante do contexto de ataques aos direitos que a população brasileira tem vivenciado, tendo como horizonte estratégico a emancipação humana.

Guzzo (2015) aponta que, para assumir um compromisso ético e político com as populações na reali- dade latino-americana, a Psicologia precisa tirar seu foco das desordens e doenças psicológicas e passar para o desenvolvimento e fortalecimento de indivíduos e grupos. Para isso, é preciso que tenha acesso a uma formação crítica, não reproduzindo os modelos colonizadores a que tivemos acesso, mas construindo compreensões e ferramentas apropriadas para os contextos em que vivemos, num processo de descolonizar a própria Psicologia.

\section{Psicologia Crítica e Educação Dialógica: fundamentos para democratização da escola}

Apesar de ainda pouco difundida no Brasil, a Psicologia Critica Alemã, desenvolvida por Klaus Holzkampe seus colaboradores, tem grandes potencialidades para a prática profissional da Psicologia nos contextos deste país. Isso porque Holzkamp, ao identificar a ausência de mundo de uma Psicologia que se desenvolve por meio de experimentos e análises em contextos artificiais (como os laboratórios e os settings terapêuticos), chama a atenção para a necessidade de a Psicologia voltar-se aos contextos cotidianos, nos quais, de fato, a vida humana acontece (Holzkamp, 2013, 2016a). Holzkamp concebe a vida cotidiana como o núcleo da vida humana, em que cada sujeito deve lidar com a complexidade de demandas dos diferentes papéis que exerce em diferentes contextos. O autor supera a compreensão das teorias sociais, de que o sujeito é subordinado à estrutura social, ao buscar compreender como ela se articula com as experiências do sujeito nas escolhas e ações cotidianas. Para isso, desenvolve uma categoria mediadora de extrema importância para a Psicologia Crítica: a condução de vida (Dreier, 2016). A categoria é aplicada e desenvolvida na análise de como os sujeitos conduzem suas vidas em colaboração com os outros, tendo em vista que o desenvolvimento das rotinas, nunca é um projeto individual (Schraube, \& Højholt, 2016). Isso coloca em evidência a dimensão social da vida humana e abre o caminho para a compreensão de como as relações de poder são exercidas nos contextos cotidianos, limitando as possibilidades de ação para o sujeito que se encontra em menor grau de poder (Dreier, 2016).

\footnotetext{
${ }^{1}$ A diferenciação entre emancipação humana e política foi discutida por Marx (1844). De forma breve, pode-se compreender que, para Marx, a emancipação política é o estágio mais avançado que se pode alcançar dentro de uma sociedade desigual, mas se organiza no interior do projeto da burguesia e não elimina a exploração do homem, enquanto a emancipação humana é muito mais integral e abrangente, eliminando pela raiz as desigualdades.
} 
A escola destaca-se como um importante contexto no qual a vida cotidiana acontece, tendo em vista que todas as crianças e adolescentes devem passar ali parte significativa de sua vida, e as relações de poder são evidenciadas todo o tempo no processo de condução de vida de estudantes e profissionais. Assim, partimos do pressuposto de que a escola é um local privilegiado para a atuação da Psicologia (Guzzo, 2014; Guzzo, Moreira, \& Mezzalira, 2015; Moreira, 2015). A Psicologia que atua neste espaço precisa enfrentar a realidade de um campo que, conforme aponta Saviani (2011), tem grande importância social e, por isso, sofre constantes ataques e retrocessos promovidos pelos detentores do poder. O autor aponta que estes ataques produzem seu sucateamento e transformação em um espaço infértil, que apenas colabora para a passividade da população.

Paulo Freire (2005), declarado em 2012 Patrono da Educação brasileira, apontava para o problema do que denominou educação bancária, em que o professor, como detentor único do saber, "deposita" os conteúdos, e aos alunos cabe arquivar as informações de forma passiva: "Não é de se estranhar que na visão bancária de educação, os homens sejam vistos como seres de adaptação, de ajustamento" (p. 68). Assim, o alvo estabelecido é a transformação da mentalidade dos oprimidos e não da situação de opressão. Para Freire (2005), a domesticação, que condiciona à passividade diante das injustiças sociais, é apenas um dos caminhos que a Educação pode seguir. $\mathrm{O}$ autor afirma que ela pode exercer um importante papel na emancipação humana, quando assume uma postura problematizadora e libertadora baseada no diálogo.

Apesar de contemporâneos, não há registros de que Paulo Freire e Klaus Holzkamp acessaram as produções um do outro, mas sua base comum em Marx possibilita uma articulação, no sentido de a Psicologia Crítica contribuir para a construção de uma educação emancipadora, em conformidade com as ideias de Freire. Holzkamp aponta que, no processo de condução de vida, as pessoas tomam parte na reprodução, nas negociações e mudanças das estruturas sociais. Para isso, precisam explorar as possibilidades no contexto das constelações de significados na cultura e estrutura social em que vivem. Ao buscar compreender porque o sujeito escolhe uma opção para agir em detrimento de outras, Holzkamp (2016b) supera a compreensão de motivação - que pressupõe uma atitude analítica da perspectiva do psicólogo, e busca as razões subjetivas para ação. A diferença é que, no discurso da razão, a resposta vem sempre em primeira pessoa - os sujeitos têm suas próprias formas de atribuir significado às suas vivências e fazer suas escolhas e, assim, a perspectiva crítica na Psicologia busca compreender a condução de vida a partir do ponto de vista dos sujeitos.

Para Holzkamp (2013), as constelações de significado podem estar tão consolidadas ao lado da estrutura social, que certas possibilidades de ação (que envolvem rupturas no processo de reprodução da sociedade) podem não serem vistas pelo sujeito, algo muito comum no modelo de educação bancária. Assim, há uma compreensão aparente de que o sujeito está fazendo escolhas livremente quando, na verdade, está sendo moldado por estas constelações de significados. Numa relação com as ideias de Freire, poderíamos compreender que, no contexto da escola, esses significados culturais engessados são reforçados para estudantes, quando o professor lhes deposita as informações, não promovendo um pensar crítico sobre a realidade. Assim, diante das limitações vividas em seu cotidiano, o sujeito que se formou num modelo de passividade buscará a superação sem ampliar o controle sobre suas condições de vida e em sujeição aos poderes existentes, algo que Holzkamp (2016a) denomina de capacidade restritiva de ação.

Segundo Holzkamp (1983), a Psicologia Crítica tem ferramentas que podem colaborar para a superação de pressões para adaptação social. Ao propor espaços de reflexão no âmbito da escola, por exemplo, este profissional possibilita que os sujeitos se ajudem mutuamente a compreender quais compromissos que contradizem seus interesses acabaram por assumir. Isso está de acordo com a proposta de Freire (1979) para uma educação dialógica, já que ela possibilita aos estudantes que desenvolvam a capacidade de refletir criticamente sobre os conhecimentos, e utilizá-la, tanto para a construção de uma gestão justa e democrática dos espaços educativos, quanto para sua atuação fora dos muros da escola. A partir da vinculação prática entre as concepções de conscientização e libertação, a educação popular contribui para a ruptura da ideia de que as condições materiais da realidade são imutáveis. A superação da alienação consiste no entendimento do homem de que a realidade é algo modificável à sua ação (Freire, 1997).

Ao tentar ampliar a compreensão sobre determinado problema, a fim de articular, coletivamente, 
ações que possibilitem a ampliação do controle dos sujeitos sobre ele, é possível sair do ciclo de lidar apenas com as situações imediatas e ampliar a noção dos eventos e forças que estão implicados na constituição do problema. Assim, a Psicologia pode criar condições para a opção dos sujeitos pela capacidade generalizada de ação, conforme denomina Holzkamp. Desta forma, o psicólogo pode contribuir para a efetivação da dialogicidade na educação, ao favorecer que os atores escolares ampliem sua capacidade de ação e conduzam sua vida de forma mais adequada aos interesses coletivos.

Passamos agora a discutir as políticas que estabelecem a gestão democrática como princípio para a Educação, tendo em vista a importância de o psicólogo que pretende contribuir para a ampliação da participação no âmbito escolar se apropriar desses espaços, endossando as políticas que resultaram de lutas da própria população pela democratização da sociedade.

\section{LDB e gestão democrática}

Conforme apontamos anteriormente, a Democracia precisa criar legislações e instrumentos que possibilitem aos cidadãos o exercício de sua vontade. Neste sentido, apresentam-se neste eixo, leis formuladas para abrir caminho à criação e ampliação de espaços participativos favorecendo a transparência e tomada de decisões na escola. Após os anos de Ditadura empresarial-militar no Brasil, como fruto de anos de discussão envolvendo as mais diversas esferas da sociedade brasileira, a Lei no 9.394/1996, que estabelece as diretrizes e bases da educação nacional (LDB), surge como um instrumento de definição no ordenamento das linhas gerais da Educação, servindo como uma resposta às necessidades sociais e políticas do país, com vistas a estabelecer uma nova ordem social e educativa, ampliando o conceito de direitos educacionais (Del Prette, 1999).

ALDB (Lei No 9.394) postula a gestão democrática como um dos princípios do ensino público (Art. $3^{\circ}-$ inciso VIII), e propõe que as normas da gestão democráticas serão definidas pelos sistemas de ensino, conforme suas peculiaridades, seguindo como princípios a participação de profissionais da educação na elaboração do projeto pedagógico da escola (inciso I) e da comunidade escolar e local nos conselhos escolares ou equivalentes.

Para Araújo (2009), a gestão democrática é, por excelência, uma estratégia de enfrentamento e supe- ração dos modelos burocráticos, hierárquicos e autoritários que se reproduzem nos espaços educativos. Considerar, portanto, a participação dos sujeitos nas decisões concernentes à escola pública é viabilizar a construção de um novo projeto de escola e sociedade, dando luz e sentido ao adjetivo público.

Na sessão em que regulamenta a organização da Educação Nacional, a Lei postula que a União deverá, em colaboração com os Estados, o Distrito Federal e os Municípios, elaborar o Plano Nacional de Educação e estabelecer "competências e diretrizes para a educação infantil, o ensino fundamental e o ensino médio, que nortearão os currículos e seus conteúdos mínimos, de modo a assegurar formação básica comum" (Lei No 9.394, Art. 9 - incisos I e IV). Aos Estados, cabe "elaborar e executar políticas e planos educacionais, em consonância com as diretrizes e planos nacionais de educação, integrando e coordenando as suas ações e as dos seus Municípios" (Art. 10 - inciso III), e aos Municípios "organizar, manter e desenvolver os órgãos e instituições oficiais dos seus sistemas de ensino, integrando-os às políticas e planos educacionais da União e dos Estados" (Art. 11 ${ }^{\circ}$ - inciso I).

Desta forma, a Lei atribui responsabilidades às esferas Nacional, Estadual e Municipal, que, seguindo os princípios da gestão democrática, devem elaborar seus planos de forma colaborativa e adequada às realidades locais. Sendo assim, ao buscar os objetivos deste trabalho, consideramos a importância de se analisar os atuais Planos elaborados pelas três esferas (Nacional, do estado de São Paulo e do município de Campinas), no sentido de buscar de que forma promovem, ou não, a participação de estudantes de ensino fundamental.

\section{Método}

\section{Fontes de informação}

A presente pesquisa organizou-se pela metodologia de caráter documental. Segundo Godoy (1995), neste tipo de pesquisa, a própria escolha dos documentos a serem analisados dá-se em função de algumas ideias e hipóteses. Para a análise no âmbito dos planos, foram utilizadas três fontes: a) o Plano Nacional de Educação (PNE); b) O Plano Estadual de Educação do Estado de São Paulo e c) o Plano Municipal de Educação do Município de Campinas, cidade onde o projeto Ecoar está inserido. 
O PNE foi instituído pela Lei $\mathrm{n}^{\circ} 13.005 / 2014$, apresenta 14 artigos e 20 metas, com vigência de dez anos (2014-2024). O Plano Estadual de Educação (PEE) constituiu-se pela Lei no ${ }^{\circ} 16.279 / 2016$ e é composto por 11 artigos e 21 metas referenciadas no PNE e na LDB, que visam subsidiar a educação básica, educação profissional e ensino superior no estado de São Paulo pelo período de 10 anos (2016-2026). O Plano Municipal de Educação (PME), instituído no município de Campinas a partir da Lei no 15.029 /2015 é composto por 18 artigos e 22 metas. Possui vigência de 10 anos (2015-2025).

Para análise dos órgãos colegiados, que garantem a participação de estudantes no município de Campinas, consultamos a Portaria da Secretaria Municipal de Educação - SME no 114/2010, que no Artigo 21º especifica os espaços participativos nas escolas.

\section{Procedimentos}

Para a análise dos planos, foram realizadas três etapas. Na primeira, buscamos nos documentos os trechos que tratam sobre a democratização da escola, a partir das palavras-chave: "Participação" (e derivados: "participar, participativo"), "Democratização" (e derivados: "democratizar", "democrática/o", "democracia”), "Conferência", "Movimento Estudantil", "Grêmio Estudantil”, “Comissão Própria de Avaliação", "Projeto Político Pedagógico" "Conselho de Ciclo" e "Conselho de Escola”. Na segunda etapa, realizamos uma leitura atenta dos trechos onde as palavras buscadas apareciam, a fim de identificar quais deles tratavam, especificamente, da participação de estudantes do ensino fundamental. A partir desta seleção, partimos para a terceira etapa, que consistiu na exposição dos trechos, e identificação dos objetivos de cada proposta e como elas sinalizam a participação de estudantes, refletindo, posteriormente, sobre a contribuição que a Psicologia pode oferecer no fortalecimento destes espaços, conforme os objetivos deste artigo.
Para a análise dos órgãos colegiados, buscou-se identificar 1. Quem os compõem (ou seja, se têm a participação de estudantes); 2 . Como seus participantes são escolhidos e 3. Quais são as competências destes órgãos.

\section{Resultados e discussão}

\section{Análise dos Planos de Educação}

A análise dos três planos permitiu a identificação de possibilidades de participação de estudantes na construção da educação em diferentes níveis. Considerando que grande parte dos planos se repete, mas há algumas diferenças, na Tabela é possível comparar as ocorrências nos artigos das leis, bem como nas metas e estratégias contidas em seus anexos.

Passaremos à exposição do conteúdo desses planos, ressaltando as semelhanças e diferenças entre eles no que se refere à promoção da participação de estudantes. Os três documentos reproduzem as mesmas sentenças no Art. $2^{\circ}$, que diz respeito às diretrizes que os guiam. Dentre elas, quatro dizem respeito à promoção da cidadania e/ ou gestão democrática:

III - superação das desigualdades educacionais, com ênfase na promoção da cidadania e na erradicação de todas as formas de discriminação; [...] $\mathrm{V}$ - formação para o trabalho e para a cidadania, com ênfase nos valores morais e éticos em que se fundamenta a sociedade; VI - promoção do princípio da gestão democrática da educação pública; [...] IX - promoção dos princípios do respeito aos direitos humanos, à diversidade étnico-racial e à sustentabilidade socioambiental (Plano Nacional de Educação, Lei No 13.005, Art. 2º).

No PME (Lei Municipal No 15.029, 2015), a parte da diretriz "IX" do PNE, que cita a diversidade étnico-racial, foi destacada na diretriz III: "superação das

Tabela

Ocorrências sobre participação de estudantes nos Planos de Educação.

\begin{tabular}{lcccr}
\hline Nome & Lei & Artigos & Metas & Estratégias \\
\hline PNE & $13.005 / 2014$ & $2^{\circ}, 3^{\circ}, 6^{\circ}, 8^{\circ}$ e $9^{\circ}$ & $4,7,19$ & $4.18,7.4,7.16,7.25,7.26,19.1,19.3,19.4,19.5,19.6$ \\
PEE & $16.279 / 2016$ & $2^{\circ}, 3^{\circ}, 5^{\circ}$ e $6^{\circ}$ & $7,17,19$ & $7.7,7.20,7.30,17.5,17.9,19.1,19.5,19.7,19.8,19.9,19.10$ \\
PME & $15.029 / 2015$ & $2^{\circ}, 3^{\circ}, 6^{\circ}, 9^{\circ}$ e $10^{\circ}$ & 7,19 & $7.3,7.4,7.12,7.17,7.22,7.35,19.6,19.7$ \\
\hline
\end{tabular}


desigualdades educacionais, com ênfase na promoção da igualdade racial, regional e diversidade" (Art. $2^{\circ}$ - inciso III). A ênfase que o município coloca na promoção da igualdade étnico-racial, leva em conta o histórico de grande opressão do povo negro na cidade. Por meio destas diretrizes, foi possível identificar uma intenção dos planos para a promoção do desenvolvimento das capacidades de participação e valores necessários para que os estudantes possam exercer a cidadania e contribuir para uma sociedade mais democrática e igualitária (Prefeitura Municipal de Campinas, 2016)..

Os artigos terceiros dos Planos estabelecem as metas e estratégias a serem desenvolvidas no decênio de suas vigências. Foram encontradas menções à participação nas metas 7 e 19 dos três planos, mas no PEE (Lei Estadual № 16.279, 2016) também houve uma ocorrência na meta 17. A meta 7 visa "fomentar a qualidade da educação básica em todas as etapas e modalidades, com melhoria do fluxo escolar e da aprendizagem" a fim de atingir as metas do Índice de Desenvolvimento da Educação Básica - IDEB (nacionais ou estaduais). Dada a extensão do documento, optou-se pela não transcrição literal de todas as estratégias, mas aponta-se, aqui, as temáticas encontradas:

1. Participação da comunidade escolar no processo de autoavaliação institucional (PNE - 7.4; PEE 7.7; PME - 7.3 e 7.4);

2. Gestão democrática dos recursos financeiros da escola (PNE - 7.16; PEE - 7.20; PME - 7.12);

3. Participação da comunidade na construção dos currículos e na gestão das escolas, respeitando as culturas tradicionais (como quilombolas e indígenas) (PNE - 7.25 e 7.26; PEE - 7.30; PME - 7.22).

4. Participação da comunidade escolar e da sociedade na definição dos parâmetros mínimos de qualidade dos serviços de educação básica como referência as escolas (PME - 7.17);

5. Formação aos membros do conselho de escola para efetivar a participação democrática (PME - 7.35).

Partimos do pressuposto que os estudantes estão inclusos quando há referências à comunidade escolar, pois poucas são as que especificam os estudantes. É possível verificar que o PME apresenta duas estratégias de participação que não constam nos outros planos. A meta 19 visa:

Assegurar condições, no prazo de 2 (dois) anos, para a efetivação da gestão democrática da edu- cação, associada a critérios técnicos de mérito e desempenho e à consulta pública à comunidade escolar, no âmbito das escolas públicas, prevendo recursos e apoio técnico da União para tanto (Lei No 13.005, 2014, Art. 3o, Meta 19).

Tratando, mais especificamente, da gestão democrática, esta meta, presente nos três planos, é a que mais traz estratégias relacionadas à participação de estudantes. As temáticas encontradas foram:

1. Agarantia da formulação de leis que promovem a gestão democrática nos sistemas de ensino (PNE - 19.1; PEE - 19.1);

2. O incentivo a construção de Fóruns Permanentes de Educação (PNE - 19.3);

3. O estímulo para constituição e fortalecimento de grêmios estudantis e associações de pais e mestres, garantindo condições para sua articulação com os Conselhos Escolares (PNE - 19.4; PEE - 19.7);

4. O estímulo à criação de conselhos escolares e conselhos de educação por meio de programas de formação de conselheiros (PNE - 19.5; PEE 19.10; PME - 19.6 e 19.7);

5. O estímulo à participação e consulta aos projetos pedagógicos por parte de profissionais da educação, estudantes e seus familiares (PNE - 19.6; PEE $-19.5,19.6$ e 19.9);

6. O fortalecimento dos espaços participativos, assegurando a representação de todos os segmentos (professores, pais, estudantes, funcionários e sociedade civil organizada) (PEE - 19.8).

Pensar a educação significa, sobretudo, pensar na diversidade cultural que caracteriza a nação brasileira e refletir sobre formas de valorizá-las. Neste sentido, Araújo (2009) chama a atenção para a necessidade de considerar o pluralismo dos contextos escolares e reitera a importância do posicionamento contra as tendências hegemônicas que "passam a régua" nos indivíduos no sentido de furtá-los de suas particularidades. Portanto, criar espaços para que a representatividade se faça presente na escola é uma tarefa imprescindível para a democratização da escola e da sociedade como um todo.

Ao segurar a representação de todos os segmentos nas decisões, as estratégias lançam luz sobre o sentido de público e democrático, uma vez que explicitam a importância do envolvimento dos membros da sociedade civil no engajamento com as questões da educação e potencializam os movimentos de supe- 
ração da gestão burocrática, hierarquizada e autoritária. Compreender a importância e necessidade do estreitamento dos vínculos entre a escola e segmentos externos a ela é um dos avanços mais significativos na discussão sobre gestão democrática, tendo em vista que disponibiliza a escola como um serviço construído pela e para a comunidade.

O PEE inova ao incluir uma estratégia participativa na meta 17: "Valorizar os profissionais do magistério das redes públicas de educação básica de forma a equiparar, no Estado de São Paulo, até o final do sexto ano de vigência do PEE, seu rendimento médio ao dos demais profissionais com escolaridade equivalente". A Estratégia incluída é a 17.5, que visa "Promover a participação de todos os atores da comunidade escolar para estudar as condições de trabalho e prover políticas públicas voltadas ao bom desempenho profissional e à qualidade dos serviços educacionais prestados à comunidade" (São Paulo, 2016, Art. $3^{\circ}$, meta 17). Apesar de não especificar os estudantes, compreende-se que eles estão incluídos em "atores da comunidade escolar" e, portanto, poderiam contribuir nas propostas referentes à valorização de seus professores.

Há nos Planos artigos referentes à promoção de conferências (nacional, estadual e municipal), a fim de avaliar os planos atuais e construir os planos do próximo decênio de forma participativa (Lei No 13.005, 2014, Art.6 e e 8; Lei Estadual oo 16.279, 2016, Art. 5; Campinas, 2015, Art. $6^{\circ}$ e $9^{\circ}$ ). Ao apropriar-se do direito de participar destes espaços para além dos muros da escola, o estudante pode aprender o processo de construção de políticas públicas, bem como exercer influências num âmbito mais amplo da sociedade.

O PEE especifica possibilidade de participação em seu acompanhamento e avaliação por meio dos conselhos escolares (Lei Estadual № 16.279, 2016, Art. $\left.6^{\circ}, \S 5^{\circ}\right)$, e, por fim, é indicada nos planos, a necessidade de cada âmbito criar leis específicas para garantir a gestão democrática em seus sistemas de ensino (Lei No 13.005, 2014, Art. 9; Campinas, 2015, Art. 10º).

\section{Espaços participativos}

Comissão Própria de Avaliação (CPA): espaço garantido no município de Campinas pela Resolução SME $n^{\circ} 05 / 2008$, que estabelece as diretrizes para a implementação do processo de Avaliação Interna das Unidades Municipais de Ensino Fundamental. A CPA deve ser constituída por, no mínimo, um representante dos segmentos de docentes, de alunos, de funcioná- rios, das famílias e da equipe gestora, tendo o(a) orientador(a) pedagógico(a) da unidade educacional como membro articulador deste processo. O principal objetivo é realizar uma autoavaliação da unidade educacional e elaborar um relatório anual sobre o cumprimento das metas propostas, visando qualificar o ensino. Tanto a avaliação quanto os relatórios da CPA devem ser divulgados a todos os membros da comunidade escolar e integrados ao Projeto Político Pedagógico da escola.

Grêmio Estudantil: um dos colegiados autônomos existentes na escola e é garantido pela Lei $\mathrm{n}^{\circ}$ 7.398. Trata-se, essencialmente, de uma organização que representa os interesses de estudantes. É um espaço em que os estudantes podem criar inúmeras possibilidades de ação tanto na escola, quanto na comunidade. O grêmio é composto somente por estudantes, que constroem chapas, eleitas por voto direto, com mandato de um ano letivo. São atribuições do grêmio: Organizar atividades de interesses dos estudantes com fins culturais, educacionais, cívico-esportivas e sociais.

Conselho de Escola: Conforme orienta a LDB (Lei No 9.394, 1996), os sistemas de ensino devem regulamentar o funcionamento do Conselho de Escola adequando-se as suas peculiaridades. Em Campinas, o Conselho de Escola foi regulamentado pela Lei $\mathrm{n}^{\circ}$ 6.662/91 e é composto por representantes de variados segmentos: direção da escola, representante da associação de moradores, professores, estudantes, familiares e funcionários. Os conselheiros devem ser eleitos por seus pares nos primeiros trinta dias do início do ano letivo. As principais atribuições do Conselho de Escola são: deliberar as normas internas de funcionamento da escola, analisar as questões encaminhadas pelos diversos segmentos da escola e criar propostas de melhorias, acompanhar a execução das ações pedagógicas, administrativas e financeiras da escola e mobilizar a comunidade escolar e local para participação de atividades de melhoria da qualidade da educação.

Conselho de Ciclo: Segundo o Regimento Escolar do Município de Campinas (Portaria SME No 114/ 2010), o Conselho de Ciclo é um colegiado responsável por decidir as ações e os encaminhamentos necessários para o desenvolvimento do processo ensino aprendizagem de todos os estudantes durante e ao fim de cada semestre/ano letivo e pela promoção ou retenção de estudantes ao fim de cada Ciclo. Pode participar a equipe gestora, os professores que atuam no mesmo Ciclo do Ensino Fundamental e os estudantes representantes de classe. As reuniões ocorrem ao 
fim de cada trimestre e ao fim do ano letivo. Todos os espaços que destacamos são recursos possíveis para que as Leis e Metas dos planos de educação que visam a democratização da escola se efetivem.

\section{Algumas considerações sobre as políticas de participação e o papel da Psicologia}

Podemos identificar, a partir das Leis, das Metas e dos espaços participativos aqui expostos, que há inúmeros esforços para o avanço da democratização da escola. No entanto, poucas são as oportunidades em que os profissionais da escola conseguem tempo para apropriar-se destas propostas, refletindo sobre a forma de efetivá-las no cotidiano escolar. Assim, questionamos se os profissionais da educação conhecem essas políticas e se têm clareza sobre o que pode ser feito em cada um dos espaços de participação. E, caso essa resposta seja negativa, como poderiam os estudantes tomar conhecimento e integrar esses espaços?

Esta pesquisa permitiu identificar que as leis preveem direitos, mas são superficiais na articulação com a prática e, assim, espera-se que nos Planos de Educação essa articulação fique mais explícita. No entanto, identificamos que, mesmo nas estratégias definidas a partir das metas (que deveriam ter caráter prático e objetivo), há poucas referências aos espaços constituídos pelas leis. Desta forma, é possível que as estratégias assumam, igualmente, uma forma de princípio geral, deixando a discussão de como efetivar as metas, ainda abstratas.

Outro ponto a ser ressaltado é a raridade em que os estudantes aparecem discriminados como protagonistas nos Planos. Neste sentido, a Psicologia tem muito a contribuir, ao fundamentar a importância da construção de espaços em que os estudantes desenvolvam sua capacidade de ação, e possam exercê-la numa modalidade mais generalizada. A escola constitui-se como um espaço complexo e com diversas demandas que tornam desafiadora a condução de vida de todos os atores ali presentes. Neste sentido, o profissional de Psicologia pode contribuir ao criar e fortalecer espaços que possibilitem uma articulação coletiva, negociação e promoção do diálogo para a solução de questões cotidianas, visando a prevenção de diversas situações produtoras de sofrimento para os sujeitos envolvidos. Além disso, o profissional pode promover formações aos educadores e estudantes, discutindo sobre os espaços existentes e as formas de participação.
Para pôr em prática esta proposta, organizamos, a partir da presente pesquisa, a cartilha "Participar da minha escola" (Meireles, Carvalho, Santos, \& Guzzo, 2017), como um instrumento de mediação para discussões sobre os espaços participativos. Voltada, principalmente, aos estudantes, a cartilha busca explicar, de forma simples, quais são as possibilidades de participação nas escolas do município de Campinas. Este material tem sido utilizado no âmbito do projeto Ecoar, mas o disponibilizamos ${ }^{2}$ para que contribua com o acesso à informação e promoção da participação de estudantes.

\section{Conclusões}

A criação de propostas que formalizam e conferem respaldo legal à participação de estudantes representa um grande avanço na construção de uma escola que forma pessoas com capacidades para atuar como cidadãs, apropriadas de uma cultura mais participativa e dialógica, e que podem, assim, contribuir para a democratização da sociedade. No entanto, se a população não se apropria destas propostas, por mais interessantes que sejam, não chegarão a se efetivar.

Do ponto de vista psicológico, destacamos a potencialidade dos espaços participativos criarem condições para que os estudantes aprendam a argumentar, negociar e cumprir negociações, encaminhar seus problemas cotidianos e criar uma escola mais interessante e que faça sentido no curso de sua vida. Estas capacidades acrescentam possibilidades às constelações de significados apresentadas aos estudantes. Diante de uma sociedade tão marcada pelo abuso de poder e por situações de violência, muitas vezes, os estudantes não veem outra saída para a resolução de problemas para além do agir restritivo que, muitas vezes, faz uso da violência e, em última instância, resulta em consequências contrárias a seus interesses. A aprendizagem do diálogo e da participação favorece que recursos como o uso da força percam sua utilidade e sejam menos escolhidos diante dos desafios cotidianos (Meireles, 2015). Ao compreender a importância da participação e se apropriar desse direito, os estudantes podem superar a ideia de que "a decisão vem de cima" e que estão ali apenas para obedecer a regras e aprender conteúdos que não lhes fazem sentido.

Por fim, considera-se que o fortalecimento dos espaços participativos pode reconfigurar a dinâmica cotidiana no interior das escolas, superando as rela-

${ }^{2}$ A cartilha pode ser acessada no site do Grupo de Pesquisa: https://goo.gl/AzebTW. 
ções de opressão e dominação que desconsideram os estudantes como sujeitos no processo de construção da escola. Fazer da escola um espaço de exercício da participação é contribuir com a formação integral de sujeitos implicados no processo da própria construção do conhecimento e da realidade, que não se deixam levar pelos poderes que os querem passivos e submissos às explorações.

\section{Referências}

Araújo, A. C. (2009). A gestão democrática e os canais de participação dos estudantes. Revista Retratos da Escola, 3(4), 253-266.

Boechat, F. M. (2017). A Psicologia brasileira nos ciclos democrático-nacional e democrático-popular. Psicologia: Ciência e Profissão, 37(num esp.), 57-70. https://doi.org/10.1590/1982-3703040002017

Dahl, R. A. (2012). A Democracia e seus críticos. São Paulo: Martins Fontes.

Del Prette, Z. A. P. (1999). Psicologia, educação e LDB: Novos desafios para velhas questões? In R. S. L. Guzzo (Org.), Psicologia Escolar e a nova conjuntura educacional brasileira (pp. 11-34). Campinas, SP: Átomo.

Dreier, O. (2016). Conduct of everyday life: Implications for critical psychology. In E. Schraube, \& C. Højholt (Orgs.), Psychology and the conduct of everyday life (p. 15-33). New York, NY: Routledge.

Freire, P. (1979). Conscientização: Teoria e prática da libertação: Uma introdução ao pensamento de Paulo Freire (17a ed). São Paulo, SP: Centauro.

Freire, P. (1997). Pedagogia da esperança: Um reencontro com a Pedagogia do oprimido. Rio de Janeiro, RJ: Paz e Terra.

Freire, P. (2005). Pedagogia do Oprimido (42a ed). Rio de Janeiro, RJ: Paz e Terra (Original publicado em 1974).

Godoy, A. S. (1995). Pesquisa qualitativa: Tipos fundamentais. Revista de Administração de empresas, 35(3), 20-29. https://doi.org/10.1590/S0034-75901995000300004

Guzzo, R. S. L. (2015). Critical psychology \& American continent: From colonization and domination to liberation and emancipation. In I. Parker (Org.), Handbook of critical psychology (pp. 406-414). New York, NY: Routledge.

Guzzo, R. S. L. (2014). Descolonizando a Psicologia: Processos de participação na escola e comunidade. Projeto de pesquisa elaborado para o processo de Bolsa Produtividade Edital CNPq, Campinas-SP.

Guzzo, R. S. L., Moreira, A. P. G., \& Mezzalira, A. S. C. (2015). Everyday life and public elementary school in Brazil: A critical psychological intervention model. Outlines - Critical Practice Studies, 16(2), 71-87.

Holzkamp, K. (2016a). Ciência Marxista do sujeito (R. S. L. Guzzo, E. A. Kawamura, J. Meireles, \& L. B. Oliveira, Trads.). Maceió, AL: Coletivo Veredas.

Holzkamp, K. (2016b). Conduct of everyday life as a basic concept of critical psychology. In E. Schraube, \& C. Højholt (Orgs.), Psychology and the conduct of everyday life (pp. 65-98). New York, NY: Routledge.

Holzkamp, K. (1983). Grundlegung der Psychologie. New York, NY: Campus.

Holzkamp, K. (2013). Psychology from the standpoint of the subject: Selected writings of Klaus Holzkamp. New York, NY: Palgrave Macmillan.

Hur, D. U., \& Lacerda Junior, F. (2017). Psicologia e Democracia: Da ditadura civil-militar às lutas pela democratização do presente. Psicologia: Ciência e Profissão, 37(num esp.), 3-10. https://doi.org/10.1590/1982-3703190002017

Lei No. 7.398, de 4 de novembro de 1985. (1985, 5 de novembro). Dispõe sobre a organização de entidades representativas dos estudantes de lo e 2o graus e dá outras providências. Diário Oficial da União.

Lei №. 9.394, de 20 de dezembro de 1996. (1996, 23 de dezembro). Estabelece as diretrizes e bases da educação nacional. Diário Oficial da União.

Lei №. 13.005, de 25 de junho de 2014. (2014, 26 de junho). Aprova o Plano Nacional de Educação - PNE e dá outras providências. Diário Oficial da União.

Lei №. 13.467, de 13 de julho de 2017. (2017, 14 de julho). Altera a Consolidação das Leis do Trabalho (CLT), aprovada pelo Decreto-Lei no 5.452, de 10 de maio de 1943, e as Leis nos 6.019, de 3 de janeiro de 1974, 8.036, de 11 de maio de 1990, e 8.212, de 24 de julho de 1991, a fim de adequar a legislação às novas relações de trabalho. Diário Oficial da União. 
Lei Municipal ${ }^{\circ}$ 6.662, de 10 de outubro de 1991. (1991). Cria o Conselho de Escola nas Unidades Educacionais do Município de Campinas. Recuperado de https://leismunicipais.com.br/a/sp/c/campinas/lei-ordinaria/1991/667/6662/ lei-ordinaria-n-6662-1991-cria-o-conselho-de-escola-nas-unidades-educacionais-do-municipio-de-campinas

Lei Municipal No 15.029, de 24 de junho de 2015. (2015). Institui o Plano Municipal De Educação, na conformidade do Artigo $6^{\circ}$ da Lei No 12.501, de 13 de março de 2016, do Município de Campinas, Estado de São Paulo, Recuperado de https:// bibliotecajuridica.campinas.sp.gov.br/index/visualizaroriginal/id/128617

Lei Estadual No 16.279, de 8 de julho de 2016. (2016). Aprova o Plano Estadual de Educação de S.Paulo e dá outras providências. Recuperado de http://www.al.sp.gov.br/repositorio/legislacao/lei/2016/lei-16279-08.07.2016.html

Lombardi, J. C., \& Lima, M. R. (2017). O Brasil republicano: Uma história de golpes de Estado. In C. Lucena, F. S. Previtali, \& L. Lucena (Orgs.), A crise da democracia brasileira (pp. 1-29). Uberlândia, MG: Navegando. Recuperado de https:/ / www.editoranavegando.com/copia-politicas-educacionais-1

Lucena, C., Previtali, F. S., \& Lucena, L. (Orgs.). (2017). A crise da democracia brasileira. Uberlândia, MG: Navegando. Recuperado de https://www.editoranavegando.com/copia-politicas-educacionais-1

Martin-Baró, I. (1990). La violencia en Centroamerica: Una vision psicosocial. Revista de Psicologia de El Salvador, 7(28), 123-141.

Marx, K. (1844). Sobre a questão judaica. São Paulo, SP: Boitempo.

Medida Provisória No 746, de 22 de setembro de 2016. (2016, 23 de setembro). Institui a Política de Fomento à Implementação de Escolas de Ensino Médio em Tempo Integral, altera a Lei no 9.394, de 20 de dezembro de 1996, que estabelece as diretrizes e bases da educação nacional, e a Lei no 11.494 de 20 de junho 2007, que regulamenta o Fundo de Manutenção e Desenvolvimento da Educação Básica e de Valorização dos Profissionais da Educação, e dá outras providências. Diário Oficial da União.

Meireles, J. (2015). Ecos da violência: A perspectiva de estudantes de uma escola pública (Dissertação de Mestrado). Centro de Ciências da Vida, Pontifícia Universidade Católica de Campinas, Campinas, SP, Brasil.

Meireles, J., Carvalho, J. P. M., Santos, H. G. F., \& Guzzo, R. S. L. (2017). Participar da minha escola. Recuperado de https://goo.gl/AZebTW

Moreira, A. P. G. (2015). Situação-limite e potência de ação: Atuação preventiva crítica em psicologia escolar (Tese de Doutorado). Centro de Ciências da Vida, Pontifícia Universidade Católica de Campinas, Campinas, SP, Brasil.

O’Donnell, G. (2011). Democracia, agência e estado: Teoria com intenção comparativa. (V. Joscelyne, Trad.). São Paulo, SP: Paz e Terra.

Ponce, A. (2005). Educação e luta de classes. São Paulo, SP: Cortez.

Portaria SME No114/2010 (2010). [Homologa o Regimento Escolar Comum das Unidades Educacionais da Rede Municipal de Ensino de Campinas]. Recuperado de http://www.campinas.sp.gov.br/uploads/pdf/550774812.pdf

Prado, M. A. M. (2014). Psicologia e políticas: entre preterições, críticas e resistências. In I. F. Oliveira, \& O. H. Yamamoto (Orgs.), Psicologia e políticas sociais: Temas em debate (pp. 9-15). Belém: ed.ufpa.

Prefeitura Municipal de Campinas. (2016). Relações étnico-raciais afro-brasileira: subsídio à ação educativa (Vol. 2). Campinas.

Proposta de Emenda à Constituição No 55, de 2016. Altera o Ato das Disposições Constitucionais Transitórias, para instituir o Novo Regime Fiscal, e dá outras providências. Recuperado de https://www25.senado.leg.br/web/atividade/materias/-/materia/127337

Resolução SME No 05/2008, de 6 de maio de 2008. (2008) Estabelece as diretrizes para a implementação do processo de Avaliação Interna das Unidades Municipais de Ensino Fundamental e para a constituição da Comissão Própria de Avaliação. Recuperado de http://www.campinas.sp.gov.br/arquivos/educacao/depto-pedagogico/ avaliacao-pedagogica/resolucao_CPA.pdf

Saviani, D. (2011). O direito à educação e a inversão de sentido da política educacional. Profissão Docente, 11(23), 45-58.

Saviani, D. (2017). O golpe parlamentar e seus impactos na educação brasileira: A crise política no Brasil, o golpe e o papel da educação na resistência e na transformação. In C. Lucena, F. S. Previtali, \& L. Lucena (Orgs.), A crise da democracia brasileira (p p. 215-232). Uberlândia, MG: Navegando.

Schraube, E., \& Højholt, C. (Orgs.). (2016). Psychology and the conduct of everyday life. New York, NY: Routledge. 
Villen, P. (2017). A crise brasileira e as rachaduras no sistema. In C. Lucena, F. S. Previtali, \& L. Lucena (Orgs.), A crise da democracia brasileira (pp. 109-125). Uberlândia, MG: Navegando. Recuperado de https://www.editoranavegando.com/copia-politicas-educacionais-1

Wood, E. M. (2003). Democracia contra capitalismo: A renovação do materialismo histórico. São Paulo, SP: Boitempo.

João Paulo Mendes Carvalho

Graduado em Psicologia pela Pontifícia Universidade Católica, Campinas - SP. Brasil.

E-mail: joaop.mcarvalho@hotmail.com

Jacqueline Meireles

Doutoranda do Programa de Pós-graduação em Psicologia da Pontifícia Universidade Católica, Campinas - SP. Brasil. E-mail: jmeireles@gep-inpsi.org

\section{Raquel Souza Lobo Guzzo}

Professora titular do Programa de Pós-graduação em Psicologia da Pontifícia Universidade Católica, Campinas SP. Brasil.

E-mail:rguzzo@puc-campinas.edu.br

Endereço para correspondência:

Laboratório de Avaliação e Medidas em Psicologia (LAMP). Pontifícia Universidade Católica-Campinas - Campus II. Avenida John Boyd Dunlop, s/n. Jardim Ipaussurama. CEP: 13012-970.

Campinas - SP. Brasil.

Recebido 30/06/2017

Reformulado 19/03/2018

Aprovado 11/04/2018

Received 06/30/2017

Reformulated $03 / 19 / 2018$

Approved 04/11/2018

Recibido 30/06/2017

Reformulado 19/03/2018

Aceptado 11/04/2018

Como citar: Carvalho, J. P. M., Meireles, J., \& Guzzo, R. S L. (2018). Políticas de participação de estudantes: Psicologia na democratização da escola. Psicologia: Ciência e Profissão, 38(2), 378-390. https://doi.org/10.1590/1982-3703002522017

How to cite: Carvalho, J. P. M., Meireles, J., \& Guzzo, R. S L. (2018). Students' participation policies: the role of psychology in the democratization of the school. Psicologia: Ciência e Profissão, 38(2), 378-390. https://doi.org/10.1590/1982-3703002522017

Cómo citar: Carvalho, J. P. M., Meireles, J., \& Guzzo, R. S L. (2018). Políticas de participación de estudiantes: Psicología en la democratización de la escuela. Psicologia: Ciência e Profissão, 38(2), 378-390. https://doi.org/10.1590/1982-3703002522017 